\title{
Responding to Campus Shootings: Two Studies Exploring the Effects of Sex and Placement Strategy on Knowledge Acquisition and Organizational Reputation
}

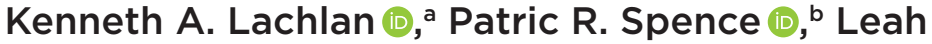 \\ Omilion-Hodges (iD, ${ }^{c}$ Robert G. Rice, ${ }^{d}$ and Amanda Brink ${ }^{e}$ \\ aDepartment of Communication, University of Connecticut, Storrs, Connecticut, \\ USA; ' ${ }^{2}$ icholson School of Communication, University of Central Florida, \\ Orlando, Florida, USA; 'School of Communication, Western Michigan University, \\ Kalamazoo, Michigan, USA; 'Division of Social Sciences, University of Pikeville, \\ Pikeville, Kentucky, USA; ' Continental Services, Troy, Michigan, USA
}

\begin{abstract}
Two separate studies used quasi-experimental procedures to examine how college students learn about campus shootings from press releases, television news, or exposure to both. The first study found that women tend to report higher levels of learning than men and that participants generally learn the most when exposed to messages delivered through multiple media. The second study extended the findings to include consideration of the impact of learning on organizational reputation. Taken together, the results of both studies offer further evidence that knowledge acquisition can help mitigate against the formation of negative impressions of an organization in crisis. They also offer that the relationship between learning and attitude formation may be mediated by sex. The results are discussed in terms of message placement strategy and sex differences in mediated learning processes. Implications for the relationship between these learning processes and organizational reputation are addressed.
\end{abstract}

KEYWORDS: Crisis communication; audience response; stakeholder communication; sex differences; crisis management

U.S. college campuses have seen an array of deadly shootings in recent years (Braggs, 2004; Kaminski, Koons-Witt, Thompson, \& Weiss, 2010; McIntyre, Spence, \& Lachlan, 2011), including more than 400 active shooter incidents between 1992 and 2015 (Mazer et al., 2015). Such situations

CONTACT Kenneth Lachlan, PhD • E-mail: kenneth.lachlan@uconn.edu • 337 Mansfield Road, Unit 1259, Storrs, CT 06269

๑ 2018 by Journal of International Crisis and Risk Communication Research. All rights reserved. 
evoke terror and uncertainty for students, faculty, administration, and the surrounding community. "Right now, I feel helpless.... I'm 22 years old and scared to be on a college campus," admitted a Northern Illinois University student when asked for her reaction to the shooting on her campus (Kelleher, 2008, para. 2). In responding to the Virginia Tech shooting, a student remarked, "You would think that a school or even a classroom would be a safe place, but over the past 10 years we have seen otherwise" (Montgomery, 2007, para. 7). Though crisis situations like school shootings often result in human losses and culminate in uncertainty for those associated with the school, organizations in crisis have the ability to foster learning for their publics, facilitate learning as a means to restore their image, and use public-focused learning as a means to grow as an organization. While past studies have relied on exposure to single stimuli or post hoc surveys to assess the impact of campus shooting messages on learning and attitudes (e.g., McIntyre et al., 2011), few have explored the impact of simultaneous stimuli delivered through different media. Furthermore, although sex differences in responses to these messages are articulated in the literature, they have for the most part been omitted from the experimental literature. The two studies herein seek to explain how organizations may create and utilize messages through varying media so that, in times of crisis, the organization is able to reduce uncertainty for stakeholders by providing accurate information. Study 2 also examines the mediating effect of sex on the relationship between knowledge acquisition and attitudes toward the organization.

\section{Campus Shootings}

Compared to other crises, little is known about communication processes associated with the crisis life cycle of campus shootings (McIntyre, Spence, \& Lachlan, 2011). In particular, there is a gap in our understanding about ideal message placement and the effectiveness of different message placement strategies in engendering learning. Omilion-Hodges and McClane (2015) extended research in this area by examining how university media selection subsequently influenced stakeholders' own choices in message content and media choice for 
information dissemination. The authors found that regardless of the initial channel through which they learned of the university crisis, students were able to retain and communicate accurate information regarding the crisis. They were also most likely to utilize a phone call or a text message to immediately connect with others before turning to social media. However, despite the fact that social media is gaining attention in the area of crisis communication and school shootings (Mazer et al., 2015; Omilion-Hodges \& McClane, 2015), legacy media are still the dominant source for information concerning most crises and disasters. Because social media often contains misinformation about crises (Lachlan et al., 2014), some organizations are understandably reluctant to adopt it as a tool for crisis communication. Moreover, it may not be an appropriate medium for postcrisis communication, as affected audiences may be more likely to resort to traditional media for expanded coverage and detailed information. It may also be the case that audiences first become aware of a crisis or risk through interpersonal exchanges, then turn to other sources for updates or additional information (see Greenberg, Hofshire, \& Lachlan, 2002; Seeger, 2006).

Although college campuses often rely on press coverage and press releases to inform the public, the question remains of which strategy is most effective in engendering learning. The current studies test the effectiveness of three different placement strategies-press release, televised news, and a combination of both-in fostering learning about a campus shooting. Furthermore, given past research suggesting sex differences in informational needs and responses following crises, the current studies investigate whether men and women will differ in terms of which medium fosters the most learning under the circumstances (Nelson, Spence, \& Lachlan, 2009; Spence et al., 2006). There is also evidence of sex differences throughout the risk sciences literature. For example, Slovic (1997) and colleagues (Finucane, Slovic, Mertz, Flynn, \& Satterfield, 2000) have offered that, on the whole, men tend to perceive risks as less threatening and may form unique opinions or vary in terms of their behavioral intentions. Given documented sex differences in both the communication and risk sciences literatures, Study 2 extends the first investigation to examine the separate and combined effects of 
gender and knowledge acquisition on subsequent attitudes toward the organization in question.

\section{Crisis Communication}

Broadly, crisis and risk communication can each be considered subcomponents of strategic communication, as they are pieces of larger scale communication plans-taking place throughout the crisis life cycle-designed to both deal with negative psychological responses and minimize the harm experienced by those affected. Given the sudden, unexpected nature of campus shootings, response messages are universally tied to the trigger event and acute crisis stage, when it has become clear that something is very wrong and that routine conditions have been cast asunder (see Fink, 1986). Under these conditions, anxiety reduction is paramount, and effective risk and crisis messages satisfy the public's need for control by offering clear, factual information that can be easily retained and acted upon. Crisis messages must detail tangible steps that can be taken by individuals to minimize their susceptibility to risk. Thus there is a critical learning component to successful crisis messages. Inaccurate or incomplete communication of risk will hinder individuals' ability to make good choices in volatile, high-risk circumstances. Of equal importance is message placement: Learning cannot take place if the message does not reach its intended audience (Lachlan \& Spence, 2014; Spence, Lachlan, \& Burke, 2011). Furthermore, it may be the case that audiences will respond differently to messages delivered in different media formats (see later), thus making placement strategy a critical consideration. Communication efforts during crises and emergencies should facilitate learning on the part of the audience, offering tangible procedural recommendations and other advice (Spence, Lachlan, \& Griffen, 2007).

A long history of research suggests that during crises and emergencies, the mass media can be expected to serve as the primary source of information for those affected (Brashers et al., 2000; Burke, Spence, \& Lachlan, 2010; Murch, 1971; Spence et al., 2006; Spence et al., 2005). The active process of searching for information through the media will bring about a sense of empowerment and control over the situation, and 
knowledge acquisition is remarkably effective in reducing uncertainty under most circumstances (Brashers et al., 2000). Acquiring information from mediated sources sets off several processes (Seeger, Sellnow, \& Ulmer, 2003), one of which is observing the behavior of others. For all intents and purposes, this is a type of learning that begets both selfefficacy and the ability to exert some control over the situation. Selfefficacy, as Bandura (1994) noted, can be described as the belief someone has about his or her capability to take an action that provides influence over events that directly affect the person's life. Bandura outlined four main sources of influence; most relevant to this study is the idea that self-efficacy can be achieved through vicarious learning or behavioral modeling. The role and benefits of self-efficacy in the crisis and risk literature are well established (Lachlan, Spence, \& Lin, 2013; Neuwirth et al., 2000; Reynolds \& Seeger, 2005; D. D. Sellnow \& Sellnow, 2014; T. Sellnow \& Sellnow, 2010, 2013; Spence, Lachlan, \& Griffen, 2007; Spence, Nelson, \& Lachlan, 2010; Witte, 1992).

Facilitating self-efficacy is considered an important aspect of numerous functional and theoretical crisis frameworks and is considered a "best practice" in crisis communication (Houston et al., 2015; Seeger, 2006; Veil, Reynolds, Sellnow, \& Seeger, 2008). Learning about a crisis can impact an individual's perception of control over the situation and reduce concerns regarding vulnerability (Seeger, 2006). When a disaster peaks, self-efficacy can be enhanced through instructional communication (Frisby, Veil, \& Sellnow, 2014; T. Sellnow \& Sellnow, 2010), such as a press release or media report. Also, engendering learning can potentially save lives by helping the public manage risk through informed decisions (Reynolds \& Seeger, 2005) and stress reduction (Veil, 2007).

When crises present some sort of real and tangible danger, people will seek information in an active and engaged manner (Brashers et al., 2000). While initial alerts may come through interpersonal channels, people typically have a repertoire of trusted sources that they will rely upon for these messages, and they will continue to scan these sources for additional information as the conditions of the crisis change (Lachlan, Spence, \& Seeger, 2009). When audiences seek information about crises and initiate learning processes, they often turn to the media (Heath, Liao, \& Douglas, 1995; Murch, 1971). 
Unfortunately, it may be the case that new media outlets underutilize the opportunity for disseminating information that can engender selfefficacy and maximize positive outcomes, perhaps owing to a lack of solidity in institutional linkages between government organizations and these outlets (see Samarajiva, 2005). Mobilizing information (Lemert, Mitzman, Seither, Cook, \& Hackett, 1977) — that which is designed to capitalize on existing schema in terms of threat location, individuals impacted, and tangible steps that can be taken-may be present in less than half of the content concerning these types of events, and online resources may be inclined to use identificational information as opposed to tactical (Tanner, Friedman, Koskan, \& Barr, 2009). However, this same research has suggested that when mobilizing information does appear, it is more likely to appear in syndicated and wire stories and is equally likely to appear in print or online (Hoffman, 2006). Thus, if such information is to be found anywhere, it may likely be located in wire stories, such as those generated by the Associated Press (AP), UPI, or Reuters.

\section{Mediated Learning Processes}

Mediated learning processes likely occur as a combination of direct instruction and observational, or vicarious, learning. Recent research in observational learning has suggested a biological component to these knowledge acquisition processes, including one that is driven by emotion and other "old-brain" functions (Rizzolatti \& Sinigaglia, 2008). This body of research, along with classical social psychology work in vicarious learning, provides both biological and behavioral explanations for learning from media (Nelson et al., 2009). Even in instances in which a person is relatively uninterested in the matter at hand, highly specified learning can still take place (Zukin \& Snyder, 1984).

As with all forms of learning, there are likely a myriad of individuallevel variables that affect learning about crises and emergencies. Of particular interest is biological sex. Although little research has directly addressed sex differences in mediated learning processes, evidence exists of consistent sex differences in preferred information sources. This research has suggested that women may be drawn to less vivid 
media for information, especially information that is particularly sensitive or issue relevant (Jensen, 1988; Keinan, Sadeh, \& Rosen, 2003; Morley, 1986).

Furthermore, there is some evidence that women may be better equipped than men to interpret nonverbal cues and may be more reliant on these cues when negotiating interactions (Burgoon \& Dillman, 1995). There is also evidence that women may be generally more risk averse than men, relationally oriented, and inclined to seek information related to both emotional needs and mitigation against risk (Burke, Spence, Lachlan, \& Seeger, 2008; Lachlan, Spence, \& Nelson, 2010; Spence, Lachlan, \& Westerman, 2009). If this is the case, then the sexes may be quite different not only in their preferred sources of information but in the observational processes they use to understand, interpret, and retain this information. Differences in preferred media sources and processing style thus necessitate an investigation of the separate and combined impacts of source and biological sex on learning. Furthermore, the preceding arguments force us to consider the role of emotion and arousal in these processes.

\section{Emotion, Arousal, and Mediated Learning}

Under conditions of extreme duress, it is typically assumed that mediated information will serve to reduce this anxiety and uncertainty. This is consistent with Weick's (1995) argument that observing the actions of others under the same circumstances can help people make sense of terrifying circumstances to which they have no understanding of how to respond. At the same time, some have argued the opposite: that media exposure may exacerbate these negative psychological responses. Some have presented evidence that repeated exposure to crisis information may itself constitute a traumatic event (Ahern, Galea, Resnick, \& Vlahov, 2004) and that repeated exposure to such information may lead to symptoms consistent with posttraumatic stress disorder (Pfefferbaum et al., 2001; Saylor, Cowart, Lipovsky, Jackson, \& Finch, 2003).

There may also be a traceable relationship between these strong emotional reactions and learning processes. Zillmann's (1999, 2002) work on exemplification theory, for example, has offered that visual 
media rely on highly emotional, arousing images that elicit immediate judgment of issues. In doing so, highly arousing imagery may lead to inaccurate perceptions of likelihood and magnitude of risk, as audiences may be inclined to generalize to entire events from a single image or message (Zillmann, 2002). Evidence of the overestimation of risk under the arousal induced by mediated exemplars is well documented in the literature (Aust \& Zillmann, 1996; Zillmann, 2002; Zillmann, Gibson, \& Sargent, 1999).

Furthermore, there is evidence that people are inclined to remember general (or "gist") information after a moderately arousing event but will lose details when pushed to extreme levels of emotional arousal (Zoladz \& Diamond, 2008). Because emotional arousal may augment or impair learning depending on the circumstances, past research has not clearly indicated how much people will learn from coverage of a crisis, especially if they are directly affected. Even less clear is the relationship between medium of choice and learning. If we are to assume that television coverage is in itself a traumatic event, as per the arguments of Ahern and colleagues (2004), then it may be the case that those watching televised coverage learn less than those who obtain information through other forms of media, such as official statements or press releases. It may also be the case that when affected publics receive information from both television and other sources, television coverage serves to attenuate the degree of learning experienced by those individuals.

Officials and organizations responding to crises must meet the public's need for information and initiate learning processes so that those affected can make sound decisions (Omilion-Hodges \& McClane, 2015). In fact, recent research (Omilion-Hodges \& McClane, 2015) has convincingly argued that organizations in crisis may in fact best meet stakeholders' need for information by involving them in the information dissemination process. Although television news coverage and official statements are the two venues through which postcrisis messages are typically transmitted under these circumstances, our knowledge of the impact of arousal suggests that other factors may be at play. If television coverage does in fact induce high levels of anxiety, it may be the case that it actually inhibits learning. Moreover, relying 
solely on television coverage reduces an organization's ability to frame messages for its stakeholders. As previously noted, past research has provided mixed results in terms of differences between men and women in learning responses. Thus, to inform future message placement strategies under these circumstances, the following research questions (RQs) are posed:

RQ1: Will audiences learn more from emergency information embedded in (a) a press release, (b) a televised news story, or (c) a combination of the two?

RQ2: Will men and women learn more from different sources?

\section{Study 1}

To explore these questions, a quasi-experiment was used to determine the effectiveness of different placement strategies in engendering learning. Participants were 180 undergraduate students at a medium-sized university in the Midwest who were randomly assigned to one of three conditions examining postevent communication. In Condition 1 , participants were asked to watch a 2-minute AP news feature about a university shooting and to fill out a self-administered survey; AP news features were used given their ecological validity as content in which mobilizing information may be embedded (Hoffman, 2006; see earlier). Condition 2 asked participants to watch the same news feature as in Condition 1, then read an official university press release designed to provided tangible safety measures, followed by a self-administered survey. Condition 3 required participants to fill out a self-administered survey after having only read the press release. The press release restated the facts of the shooting and outlined measures of self-efficacy individuals can take to protect themselves. The news clip included a short message from the university's president explaining safety procedures on campus, followed by faculty members and students explaining if they felt safe or not prior to and following the shooting. The video ended with a narrator explaining the university's capabilities for maintaining safety on campus. 


\section{Measures}

After viewing the induction, participants were asked to fill out a selfadministered survey evaluating their responses to the stimuli. These responses included a series of items measuring learning from the press release and the news clip, adapted from previous research (McIntyre et al., 2012; Nelson et al., 2009). For each medium, respondents were asked if they learned something about their university's emergency response, how people can protect themselves during a shooting, how lockdowns work, how they should respond in a similar situation, more about their personal safety, how they should travel around campus, and how to help others during a shooting; respondents replied on a 5-point Likert scale ranging from 1 (strongly agree) to 5 (strongly disagree). Items from each of these subscales were averaged to produce a scale for learning from TV $(\alpha=.78)$ and learning from the press release $(\alpha=.82)$.

\section{Results}

The questionnaire included demographic items, including information such as race, gender, and age. Caucasian $(n=136,79.1 \%)$ was reported as the highest, followed by African American $(n=19,11 \%)$, other $(n=13,7.6 \%)$, and, finally, Asian American $(n=4,2.3 \%)$. Women $(n=114,63.7 \%)$ participated more in this study than men $(n=65$, $36.3 \% ; M=1.64$ ). A total of 56 participants were assigned to the TVonly condition, 64 were assigned to the combined condition, and 60 were assigned to the press release condition. Participant ages ranged from 18 to 56 years, with a mean of 20.69 .

The RQs were examined using a series of $t$-tests. For the first research question, the condition in which participants were administered both the press release and the television news story was used as a comparison group. Against this group, the mean score for learning from the media was compared with the television-only condition. The dependent variable for learning from the press release was evaluated by comparing this group to the press release-only group.

For learning from media, the results indicate that those in the TVonly condition reported less learning $(M=3.7, S D=0.7)$ than those in the combined condition $(M=3.0, S D=0.8), t(114)=5.34, p<.001$. For learning from the press release, those in the press release-only condition 
also reported less learning $(M=2.4, S D=0.5)$ than did those in the combined condition $(M=2.00, S D=0.6), t(117)=3.75, p<.001$. As an exploratory analysis, an aggregate measure of learning was computed by taking the mean score across all learning items in the analysis. A one-way analysis of variance (ANOVA) then compared the mean scores across all three conditions. A priori power analysis performed using $G^{\star}$ Power (see Faul, Erdfelder, Lang, \& Buchner, 2007) demonstrated marginally adequate power for effect sizes as small as .05, $1-\beta=.77$. The results indicated strong effects for condition on total learning, $F(2,177)=32.66, p<.001, \eta^{2}=.54$. Bonferroni post hoc analyses revealed that those in the TV-only condition $(M=3.7, S D=0.7)$ reported learning substantially less than those in the press release $(M=2.4$, $S D=0.5)$ or combined condition $(M=2.5, S D=0.5)$.

To explore the second research question, a $3 \times 2$ ANOVA explored the impact of condition and sex on the aggregate learning measure. Power analysis suggested $1-\beta=.85$ for each main effect and $1-\beta=.77$ for the interaction effect between sex and condition. The results indicate main effects for participant sex, $F(1,178)=6.57, p<.01, \eta^{2}=.04$, and condition, $F(2,178)=98.37, p<.001, \eta^{2}=.53$, but no interaction effect between the two, $F(2,178)=.735, p<.472$, n.s. The results of this analysis provide further support for the findings from RQ1. Furthermore, men learned significantly less on the whole $(M=3.0, S D=0.3)$ than did women $(M=2.8, S D=0.2)$.

\section{Study 2}

The results of Study 1 offer preliminary insights into the role of message order in the learning processes associated with crises and disasters. They also underscore the importance of providing information concerning organizational response to a developing crisis, in an environment in which the news media will likely paint an unflattering portrait of the organization in question.

Each audience has unique needs for information, while media outlets also have specific agendas after the initial crisis event (Omilion-Hodges \& McClane, 2015). In a volatile crisis, immediate and timely information is needed about the event, and the media can become a first source for 
what actions to take (McIntyre et al., 2012; Nelson et al., 2009). The literature supports the notion that learning can be fostered at any point throughout the crisis life cycle. When an organization has caused or is perceived to have caused a crisis, it must respond with accounts, excuses, or actions to repair or retain its image (Benoit, 1995, 1997). However, one area that has not received attention is the relationship between an organization's attempt to foster learning it its publics after a crisis and organizational image (public reputation). Unflattering depictions of the organization typically take place in the later stages of an organizational crisis, when the public has developed a more comprehensive understanding of the events that took place and their ramifications for various stakeholders. Study 2, then, attempted to replicate and extend the findings from the first study by fully crossing the design in terms of the presentation of a news feature and press release. Study 2 also sought to examine the subsequent impact of learning on participants' perceptions of the organization. In an attempt to replicate the results of Study 1 and to extend the findings to include consideration of the impact of learning on organizational image, the following hypotheses and RQ are offered:

H1: Participants who are provided a press release from an organization in the aftermath of a crisis will have more positive perceptions of the organization than participants who are not provided a press release. H2: Participants receiving the press release before watching a news report about a crisis will have more positive perceptions of the organization than those who read the press release after watching the news report.

H3: Women will learn more about the organization regardless of the presence of a press release or order of presentation.

$\mathbf{R Q}$ : What is the separate and combined impact of order of presentation and biological sex on learning and perceptions of the organization?

\section{Method}

Participants. A total of 203 participants from undergraduate communication courses took part in the current study; students were drawn from the same required course as in Study 1, but more than a year later; 
thus it is highly unlikely that any student participated in both. Of the 203 participants, $29.7 \%(n=58)$ were men, with 70.3\% $(n=137)$ female participants (8 gave no response), with a mean age of 22.89 years $(S D=5.42)$.

Procedure. Participants were provided the study's URL, where they were randomly assigned to one of four conditions examining postevent communication. The intricacies of each condition are described in the following pages; however, participants in each condition completed an identical self-administered survey after being subjected to the stimulus. Participants in Condition 1 watched a 2-minute news feature from the AP about a university shooting, whereas participants in Condition 2 watched the same news feature but also subsequently received a press release that reiterated the facts of the shooting. Additionally, the press release provided tangible safety measures a person could take during campus shootings to protect himself or herself and increase his or her self-efficacy. In Condition 3, participants received the press release before watching the news feature that was utilized in Conditions 1 and 2. In Condition 4, participants were only administered the press release and asked to fill out the questionnaire.

Instrumentation. To examine perceived learning from the AP news feature in Conditions 1, 2, and 3, participants were presented with seven Likert-type questions on a 5-point scale ranging from 1 (strongly agree) to 5 (strongly disagree). Questions included topics asking if respondents learned how to protect themselves, how lockdowns work, how to help others, about personal safety, about campus travel after a shooting, about university emergency response, and how to respond in a similar situation. The questions were also used in Conditions 2, 3, and 4 to obtain data about perceived learning from the university press release. Items from each of these subscales were averaged to produce a scale for learning from TV $(\alpha=.77)$ and learning from the press release $(\alpha=.90)$.

To examine participants' perceptions of the organization, 12 items were adapted from the Organizational Reputational Scale (Coombs $\&$ Holladay, 1996). The items were measured on a 5-point Likert-type scale ranging from 1 (strongly agree) to 5 (strongly disagree). Items such as "This organization is basically honest" and "I do not trust the organization to tell the truth about this incident" are typical of the scale. Alpha reliabilities for the Organizational Reputational Scale were $\alpha=.81$. 


\section{Results}

The analyses began with a simple bivariate correlation looking at the relationship between the dependent variables under consideration. The indicator for total knowledge was strongly correlated with attitudes toward the university in the AP news feature, $r=-.190, p<.008$. Given that the knowledge items were reverse scored, this indicated that those who acquired more information tended to hold higher opinions of the university. Next, hierarchical regression analyses were conducted examining the effect of condition on both learning and attitudes toward the institution. A priori power was determined to be $1-\beta=.73$ for effect sizes of .05. First, participant age, sex, and income were entered on the first block to serve as control variables. Condition was then added to the second predictor block to examine the difference in variance accounted for in the two models.

For aggregated learning, the first predictor block failed to account for a significant proportion of the variance, $F(3,184)=1.34$, n.s. However, adding condition to the second predictor block did produce a significant model, $F(4,184)=2.39, p<.04, \Delta R^{2}=.03$. Similar results were detected for attitudes toward the university. The first block failed to produce a significant model, $F(3,184)=2.20$, n.s., while adding condition to the predictor block significantly improved the model, $F(4,184)=3.50$, $p<.009, \Delta R^{2}=.08$.

Given that the dependent variables were significantly correlated, a multivariate analysis of variance (MANOVA) was then conducted to examine the means for both dependent variables across all four conditions; power analysis indicated $1-\beta=.73$. While the analysis for learning did not produce significant results, $F(3,195)=1.62$, n.s., the model did account for $3 \%$ of the variance and indicates some evidence of linear trend in the data; the least amount of learning was reported in the feature-only condition, $M=2.42, S D=.743$, followed by those who saw the feature and then read the press release $(M=2.31, S D=$ $.469)$, then those who read the press release before seeing the feature $(M=2.23, S D=.465)$, with the greatest amount of learning taking place in the press release-only condition $(M=2.155, S D=.581)$.

Significant effects were detected for attitudes toward the institution, $F(3,195)=2.43, p<.05, \eta^{2}=.04$. The pattern of means suggested a pat- 
tern consistent with the relationship between knowledge and attitudes. Those in the feature-only condition reported the least positive attitudes toward the institution $(M=3.35, S D=.495)$, followed by those who saw the feature and then read the press release $(M=3.47, S D=.422)$, then those who read the press release before seeing the feature $(M=3.53$, $S D=.510$ ), with the most positive attitudes found in the press releaseonly condition $(M=3.64, S D=.433)$.

\section{Path Analysis}

Following the consistency in the findings across both studies, a path analysis was used to investigate the separate and combined effects of presentation order and learning on perceptions of the organization. Given past research indicating that men and women process risk information differently, and that women may be more inclined to experience both empathic responses to risk messages and internalize more information, the indirect effects of gender on organizational image were also included in the model (see Lachlan et al., 2010; McIntyre et al., 2011; Spence, Lachlan, Nelson, \& Shelton, 2010; Spence et al., 2009).

Evidence was found to support the proposed model, CMIN $/ d f=1.76$, RMSEA $=.06$, CFI $=.91$. Statistically significant paths were detected between experimental condition and learning, $\beta=-.168, p<.02$; condition and image, $\beta=.163, p<.02$; and learning and image, $\beta=-.142$, $p<.05$. Standardized indirect effects of .03 were detected for both condition and sex on image, mediated by learning. Given the scoring of the indicators, order of presentation led to greater learning about the circumstances surrounding the shooting, and this knowledge was positively related to impressions formed of the institution. Female respondents were more likely to acquire information concerning the shooting, and subsequently, those who did were slightly less likely to form unfavorable opinions about the institution (see Figure 1). 


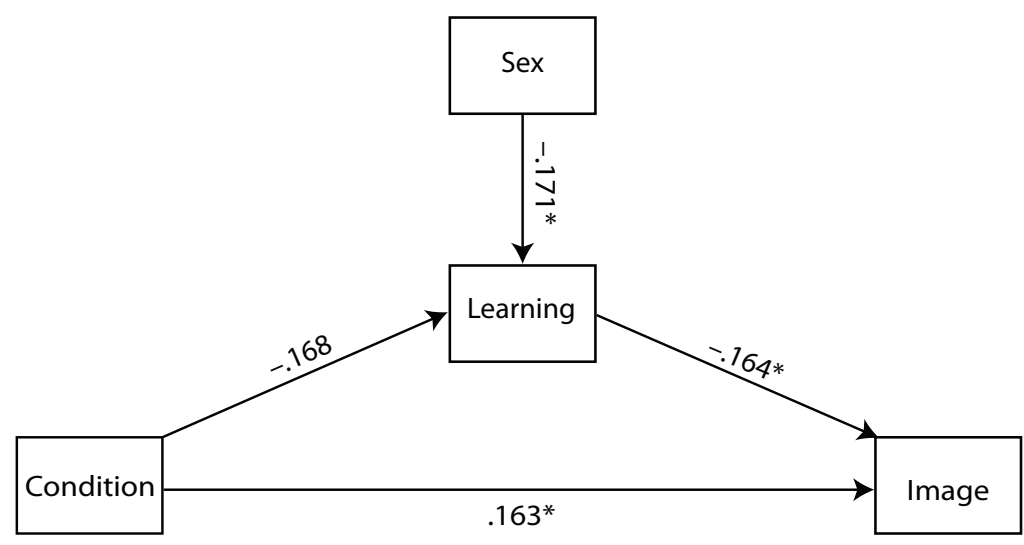

$\mathrm{CMIN} / \mathrm{df}=1.76$

RMSEA $=.06$

$\mathrm{CFI}=.910$

FIGURE 1 The effects of presentation order and learning on image.

\section{Discussion}

Taken together, the results offer some initial insight into both the message placement strategies that may facilitate learning in the aftermath of a crisis and differences between men and women in their learning responses and subsequent assessments of the organization in question. The results are in some ways surprising and in others shed new light on contradictory arguments in the literature.

First, the findings concerning medium and placement shed some light on discrepancies in past research concerning the role of television in mediated learning processes. Although a substantial body of research has suggested that people use the news media to reduce uncertainty following crises, there is also some evidence in the literature that the use of television news in particular may lead to negative emotional and psychological reactions. These negative emotional and psychological reactions, if demonstrated, would logically predict that less learning would take place from television than from other, less vivid media.

The current findings suggest that this may be the case. In both comparative analyses, individual respondents reported more learning 
when print press releases and television media were combined than from television alone. In other words, the aggregate presentation of information leads to learning. At the same time, the analyses comparing all conditions in both studies seem to indicate that audiences learned the least in the television-only condition. This would suggest that the television-only condition may be heavy on images and content that participants found to be distressing. In instances in which simple written descriptions were given through a press release, or in which emotionally disturbing video content was accompanied by factual written information, respondents reported learning more. It is worth noting that this finding is largely supportive of the argument that individuals may learn less from television if the graphic and vivid nature of the medium leads to emotional and psychological distress.

If this is the case, the findings from both studies also shed light on the degree of arousal that may be expected by different mediated accounts of a crisis. Because past research has suggested that emotional arousal augments or impairs learning, it may be the case that printed information concerning a crisis of this magnitude is alarming enough; presenting graphic and vivid images of the threatening and uncertain crisis, without complementing them with "cool" media accounts of the events, may lead to an excessive level of arousal that inhibits learning. This would be consistent with the curvilinear relationship between arousal and learning posited by numerous authors (see Zoladz \& Diamond, 2008).

The analyses in both studies also shed light on the sex differences, or perhaps lack thereof, that may be expected under the circumstances. The ANOVA analysis for sex and condition in Study 1 revealed strong main effects for both factors but not a significant interaction term between the two. This finding is supported in Study 2, where the path analysis reveals a mediation process whereby women are learning more about the organization and are therefore forming less unfavorable opinions, regardless of condition. This is somewhat consistent with past research indicating that women are prone to seek more information during crises. If this is the case, it may be that women are more prone to actually attend to the information given their standing desire for information on the matter.

What is not consistent with past research, however, is the absence 
of an interaction effect between sex and medium. Past research has suggested that women may respond more favorably to less vivid media. This body of research has also suggested that while women place a value on both vivid and nonvivid media, they may be less interested in television news, attend to less television news, and express a preference for other media. In this instance, women were just as likely as men to have learned more from the combined condition. For both sexes, in both sets of analyses, the least amount of learning was reported in the $\mathrm{TV}$-only condition. One explanation for this observation may be that women's desire for information cancels out any differences in medium preference. In other words, if we know that women are more likely to want information, and we know that men prefer vivid media, it may be the case that women's desire for information attenuates any difference in channel preference.

There are limitations with the current studies, as they only explore the responses of men and women to particular media. Radio, e-mail, the Internet, and other media are not considered in the current data. While this decision was made because crisis practitioners typically rely on these specific media when disseminating crisis information, it would be of worth to replicate the study across multiple media to investigate which combination of media makes the most sense in terms of message placement. Furthermore, the studies are confined to news coverage of one particular incident type and were not conducted on the campuses in which the incidents took place. Participants were asked how they would respond under the circumstances but were not actually in the middle of a crisis themselves when responding. Future studies should attempt to gather data from those who have been immediately affected by crisis to shine more light on these mediated learning processes. Nonetheless, the authors would argue that these studies, taken together, are a good first step in evaluating ideal message placement strategy following a crisis and the differences between men and women that may be relevant considerations under the circumstances.

\section{Practical Implications}

The current findings also offer practical implications for organizations dealing with crises and, more specifically, for college campuses 
preparing for and responding to active shooter incidents. More than anything, they offer empirical support for the long-standing maxim that organizations facing crises need to provide information quickly, not only to ensure the safety of those impacted by the crisis but also to bolster their reputation to the extent possible. The current findings suggest that getting information to the public ahead of some kind of news report may impact both retention of information and attitudes toward the institution. In this sense, organizations in crisis have the ability to frame their messages in the manner of their own choosing, allowing them to play a more active role in shaping stakeholders' understanding of the event and their perception of the organization. Thus organizations in the midst of a crisis may benefit by disseminating quick and accurate information, because this same language is likely to be recycled by the external news media.

In terms of the sex differences reported in the current studies, both crisis communication practitioners and first responders should consider that men are less likely to retain information concerning the event and more likely to form negative opinions regarding the organization. Thus information campaigns and responses may wish to appeal to men in terms of providing information to reduce anxiety, promote learning, and develop a more positive impression of the organization. Audiences will be better able to make rational decisions under equivocal circumstances if they are provided with information and brought around to an appropriate level of arousal and fear (see Lachlan \& Spence, 2007, 2009, 2010).

\section{Conclusion}

The findings of both studies add some degree of empirical evidence to old public relations maxims that have been followed for decades; as an organization experiencing crisis, it may be best to tell a story before the news media gets a chance to do so, or at the very least, an organization should present its response alongside media reports. The current findings offer evidence not only that this is important but that it may be particularly risky to issue no response at all. These findings are, however, restricted to one particular crisis scenario and explore the 
use of ecologically valid, yet situationally specific messages. The extent to which these findings can be replicated to other campus shootings, and across other types of emergencies that take place with little to no warning, remains to be seen. It is also the case that campuses do not respond to emergencies in a vacuum; while the current studies build on previous work by exploring responses to multiple messages, the number of messages and their placement were chosen in an attempt to create easily manipulated quasi-experimental conditions; future studies should vary the number of messages, media, and content characteristics to further explicate these complex processes. Finally, researchers and practitioners alike may wish to consider replicating these findings and extending them to other, less volatile crisis scenarios to examine whether the presentation order and sex differences documented herein replicate across organization, crisis type, and stakeholder group.

Kenneth Lachlan, $\mathrm{PhD}$, is professor and department head in the Department of Communication at the University of Connecticut and editor of Communication Studies. He holds research affiliations with UConn's Institute for Collaboration on Health, Intervention, and Policy and the Communication and Social Robotics Labs. His current research interests include the functions and effects of social media during crises and disasters and the use of social robotics in delivering risk messages.

Patric R. Spence, $\mathrm{PhD}$, is associate professor in the Nicholson School of Communication at the University of Central Florida. His work centers on crisis and risk communication, specifically examining the roles of government, news media, and emergency management organizations during extreme events. Recent research investigates the uses, effects, and best practices of social media in risk and crisis contexts. He works with a team of researchers from the Communication and Social Robotics Labs (http://www.combotlab.org/), focusing on human-machine communication. 
Leah M. Omilion-Hodges, $\mathrm{PhD}$, is associate professor in the School of Communication at Western Michigan University. Her research focuses on leadership and health communication within the larger context of organizational communication. Her work explores workgroup dynamics within applied settings to examine the influence of leader-member, peer, and team associations on relationship development, status distinctions, and resource sharing. More recently, she has parlayed her leadership and group work within the palliative care setting, working with national samples of practitioners to explore the nuances of this medical specialty.

Robert G. Rice, MA, is visiting assistant professor in the Division of Social Sciences at the University of Pikeville. He is a current $\mathrm{PhD}$ candidate in the College of Communication and Information at the University of Kentucky. His research focuses on risk, crisis, and disaster communication in social media. More specifically, his research interests involve the study of exemplification effects in online environments in public relations contexts and disaster life cycles.

Amanda Brink, MA, is a recruiting manager at Continental Services, Troy, Michigan.

\section{ORCID}

Kenneth A. Lachlan (1D https://orcid.org/oooo-0o02-7856-2797

Patric R. Spence (1) https://orcid.org/oooo-0002-1793-6871

Leah Omilion-Hodges (D) https://orcid.org/oooo-0oo1-5574-5155 


\section{References}

Ahern, J., Galea, S., Resnick, H., \& Vlahov, D. (2004). Television images and probable posttraumatic stress disorder after September 11. Journal of Nervous and Mental Disease, 192, 217-226. https://doi.org/10.1097/01 .nmd.oooo116465.99830.ca

Aust, C. F., \& Zillmann, D. (1996). Effects of victim exemplification in television news on viewer perception of social issues. Journalism \& Mass Communication Quarterly, 73, 787-803. https://doi.org/10.1177/107769909607300403

Bandura, A. (1994). Self-efficacy. In V. S. Ramachaudran (Ed.), Encyclopedia of human behavior (Vol. 4, pp. 71-81). New York, NY: Academic Press.

Benoit, W. L. (1995). Accounts, excuses, apologies: A theory of image restoration discourse. Albany, NY: State University of New York Press.

Benoit, W. L. (1997). Image repair discourse and crisis communication. Public Relations Review, 23, 177-186. https://doi.org/10.1016/So363-8111(97)90023-0

Braggs, D. (2004). Webcams in classrooms: How far is too far? Journal of Law and Education, 33, 275-282.

Brashers, D. E., Neidig, J. L., Haas, S. M., Dobbs, L. K., Cardillo, L. W., \& Russell, J. A. (2000). Communication in the management of uncertainty: The case of persons living with HIV or AIDS. Communication Monographs, 67(1), 63-84. https://doi.org/10.1080/03637750009376495

Burgoon, J. K., \& Dillman, L. (1995). Gender, immediacy, and nonverbal communication. In P. J. Kalbfleisch \& M. J. Cody (Eds.), Gender, power, and communication in human relationships (pp. 63-81). Hillsdale, NJ: Lawrence Erlbaum.

Burke, J. A., Spence, P. R., \& Lachlan, K. A. (2010). Crisis preparation, media use, and information seeking during Hurricane Ike: Lessons learned for emergency communication. Journal of Emergency Management, 8, 27-37. https://doi.org/10.5055/jem.2010.0030

Burke, J. A., Spence, P. R., Lachlan, K. A., \& Seeger, M. W. (2008). Sex and age differences in use and perceptions of emergency messages during Katrina. Louisiana Journal of Communication, 10, 19-33.

Coombs, W. T., \& Holladay, S. J. (1996). Communication and attributions in a crisis: An experiment study in crisis communication. Journal of Public Relations Research, 8, 279-295. https://doi.org/10.1207/s1532754xjprro804_04 Faul, F., Erdfelder, E., Lang, A. G., \& Buchner, A. (2007). G*Power 3: A flex- 
ible statistical power analysis program for the social, behavioral, and biomedical sciences. Behavior Research Methods, 39, 175-191. https://doi .org/10.3758/BFo3193146

Fink, S. (1986). Crisis management: Planning for the inevitable. New York, NY: AMACOM.

Finucane, M. L., Slovic, P., Mertz, C. K., Flynn, J., \& Satterfield, T. A. (20oo). Gender, race, and perceived risk: The "White male" effect. Health, Risk, and Society, 2, 159-172. https://doi.org/10.1080/713670162

Frisby, B. N., Veil, S. R., \& Sellnow, T. L. (2014). Instructional messages during health-related crises: Essential content for self-protection. Health Communication, 29, 347-354. https://doi.org/10.1080/10410236.2012.755604

Greenberg, B. S., Hofshire, L., \& Lachlan, K. A. (2002). Diffusion, media use, and interpersonal communication behavior. In B. S. Greenberg (Ed.), Communication and terrorism (pp. 3-16). Cresskill, NJ: Hampton Press. Heath, R. L., Liao, S., \& Douglas, W. (1995). Effects of perceived economic harms and benefits on issue involvement, information use and action: A study in risk communication. Journal of Public Relations Research, 7, 89-109. https://doi.org/10.1207/s1532754xjprro702_01

Hoffman, L. H. (2006). Is Internet content different after all? A content analysis of mobilizing information in online and print newspapers. Journalism \& Mass Communication Quarterly, 83(1), 58-76. https://doi.org /10.1177/107769900608300105

Houston, J. B., Hawthorne, J., Perreault, M. F., Park, E. H., Goldstein Hode, M., Halliwell, M. R., ... Griffith, S. A. (2015). Social media and disasters: A functional framework for social media use in disaster planning, response, and research. Disasters, 39(1), 1-22. https://doi.org/10.1111/disa.12092

Jensen, K. B. (1988). News as a social resource: A qualitative empirical study of the reception of Danish television news. European Journal of Communication, 3, 275-301.

Kaminski, R. J., Koons-Witt, B. A., Thompson, N. S., \& Weiss, D. (2010). The impacts of the Virginia Tech and Northern Illinois University shooting son fear of crime on campus. Journal of Criminal Justice, 38, 88-98. https:// doi.org/10.1016/j.jcrimjus.2009.11.011

Keinan, G., Sadeh, A., \& Rosen, S. (2003). Attitudes and reactions to media coverage of terrorist acts. Journal of Community Psychology, 31, 149-165. https://doi.org/10.1002/jcop.10040 
Kelleher, J. (2008, February 15). Fear, emptiness after deadly U.S. college shooting. Retrieved from http://www.reuters.com/article/2008/o2/15/idUSN15604771 Lachlan, K. A., \& Spence, P. R. (2007). Hazard and outrage: Developing, validating, and testing a psychometric instrument in the aftermath of Katrina. Journal of Applied Communication Research, 35, 109-123. https:// doi.org/10.1080/00909880601065847

Lachlan, K. A., \& Spence, P. R. (2009). Emergency communication: A framework for planning and targeting messages. Journal of Emergency Management, 7, 69-72.

Lachlan, K. A., \& Spence, P. R. (2010). Communicating risks: Examining hazard and outrage in multiple contexts. Risk Analysis, 30, 1872-1886. https://doi .org/10.1111/j.1539-6924.2010.01511.x

Lachlan, K. A., \& Spence, P. R. (2014). Does message placement influence risk perception and affect? Journal of Communication Management, 18, 122-130. https://doi.org/10.1108/JCOM-12-2012-0097

Lachlan, K. A., Spence, P. R., \& Lin, X. (2013). Self-efficacy and learning processes associated with the elderly during disasters and crises. In B. Raskovic \& S. Mrdja (Eds.), Natural disasters: Prevention, risk factors, and management (pp. 327-338). New York, NY: Nova Science.

Lachlan, K. A., Spence, P. R., Lin, X., \& Del Greco, M. (2014). Screaming into the wind: Twitter use during Hurricane Sandy. Communication Studies, 65, 500-518. https://doi.org/10.1080/10510974.2014.956941

Lachlan, K. A., Spence, P. R., \& Nelson, L. (2010). Gender differences in negative psychological responses to crisis news: The case of the I-35W collapse. Communication Research Reports, 27, 38-48. https://doi.org/10.108o /08824090903293601

Lachlan, K. A., Spence, P. R., \& Seeger, M. (2009). Terrorist attacks and uncertainty reduction: Media use after September 11th. Interdisciplinary Research on Terrorism and Political Violence, 1, 101-11o. https://doi .org/10.1080/19434470902771683

Lemert, J. B., Mitzman, B. N., Seither, M. A., Cook, R., \& Hackett, R. (1977). Journalists and mobilizing information. Journalism \& Mass Communication Quarterly, 54, 721-726.

Mazer, J. P., Thompson, B., Cherry, J., Russell, M., Payne, H. J., Gail Kirby, E., \& Pfohl, W. (2015). Communication in the face of a school crisis: Examining the volume and content of social media mentions during active 
shooter incidents. Computers in Human Behavior, 53, 238-248. https://doi .org/10.1016/j.chb.2015.06.040

McIntyre, J. J., Lachlan, K. A., \& Spence, P. R. (2012). Attending to the future: The role of learning in emergency response. Journal of Emergency Management, 10, 41-52. https://doi.org/10.5055/jem.2012.0085

McIntyre, J. J., Spence, P. R., \& Lachlan, K. A. (2011). Media use and gender differences in negative psychological responses to a shooting on a university campus. Journal of School Violence, 10, 299-313. https://doi.org/10.1080 $/ 15388220.2011 .578555$

Montgomery, J. (2007, April 17). Students from across U.S. respond to shootings: "It is beyond unsettling." Retrieved from http://www.mtv.com/news /articles/1557429/students-from-across-us-respond-shootings.jhtml

Morley, D. (1986). Family television: Culture, power, and domestic leisure. London, England: Routledge.

Murch, A. W. (1971). Public concern for environmental pollution. Public Opinion Quarterly, 35, 100-106.

Nelson, L. D., Spence, P. R., \& Lachlan, K. A. (2009). Learning from the media in the aftermath of a crisis: Findings from the Minneapolis bridge collapse. Electronic News, 3, 176-192. https://doi.org/10.1080/19312430903300046

Neuwirth, K., Dunwoody, S., \& Griffin, R. J. (2000). Protection motivation and risk communication. Risk Analysis, 20, 721-734. https://doi.org/10.1111/0272 $-4332.205065$

Omilion-Hodges, L. M., \& McClane, K. L. (2015). University use of social media and the crisis lifecycle: Organizational messages, first information responders' reactions, reframed messages and dissemination patterns. Computers in Human Behavior, 54, 630-638.

Pfefferbaum, B., Nixon, S. J., Tivis, R. D., Doughty, D. E., Pynoos, R. S., Gurwitch, R. H., \& Foy, D. W. (2001). Television exposure in children after a terrorist incident. Psychiatry, 64, 202-211. https://doi.org/10.1521 /psyc.64.3.202.18462

Reynolds, B., \& Seeger, M. W. (2005). Crisis and emergency risk communication as an integrative model. Journal of Health Communication, 10, 43-55. https://doi.org/10.1080/10810730590904571

Rizzolatti, G., \& Sinigaglia, C. (2008). Mirrors in the brain: How our minds share actions and emotions (F. Anderson, Trans.). New York, NY: Oxford University Press. 
Samarajiva, R. (2005). Policy commentary: Mobilizing information and communications technologies for effective disaster warning: Lessons from the 2004 tsunami. New Media \& Society, 7, 731-747. https://doi.org/10.1177 $/ 1461444805058159$

Saylor, C. F., Cowart, B. L., Lipovsky, J. A., Jackson, C., \& Finch, A. J. (2003). Media exposure to September 11: Elementary school students' experiences and posttraumatic symptoms. American Behavioral Scientist, 46, 1622-1642. https://doi.org/10.1177/0002764203254619

Seeger, M. W. (2006). Best practices in crisis communication: An expert panel process. Journal of Applied Communication Research, 34, 232-244. https:// doi.org/10.1080/00909880600769944

Seeger, M. W., Sellnow, T., \& Ulmer, R. R. (2003). Communication and organizational crisis. Westport, CT: Praeger.

Sellnow, D. D., \& Sellnow, T. L. (2014). Instructional principles, risk communication. In T. L. Thompson (Ed.), Encyclopedia of health communication (pp. 1181-1182). Thousand Oaks, CA: Sage.

Sellnow, T., \& Sellnow, D. (2010). The instructional dynamic of risk and crisis communication: Distinguishing instructional messages from dialogue. Review of Communication, 10, 112-126. https://doi.org/10.1080/153585909 03402200

Sellnow, T., \& Sellnow, D. (2013). The role of instructional risk messages in communicating about food safety. Food Insight: Current Topics in Food Safety and Nutrition, 3. Retrieved from http://www.foodinsight.org/The_Role_of _Instructional_Risk_Messages_in_Communicating_about_Food_Safety

Slovic, P. (1997). Trust, emotion, sex, politics, and science: Surveying the risk assessment battlefield. In M. H. Bazerman, D. M. Messick, A. E. Tenbrunsel, \& K. A. Wade-Benzoni (Eds.), Environment, ethics, and behavior (pp. 277-313). San Francisco, CA: New Lexington.

Spence, P. R., Lachlan, K. A., \& Burke, J. A. (2011). Differences in crisis knowledge across age, race, and socioeconomic status during Hurricane Ike: A field test and extension of the knowledge gap hypothesis. Communication Theory, 21, 261-278. https://doi.org/10.1111/j.1468-2885.2011.01385.x

Spence, P. R., Lachlan, K. A., \& Griffen, D. (2007). Crisis communication: Race and natural disasters. Journal of Black Studies, 37, 539-554. https:// doi.org/10.1177/0021934706296192

Spence, P. R., Lachlan, K. A., Nelson, L., \& Shelton, A. K. (2010). Age, gen- 
der, and information seeking patterns following an urban bridge collapse. Journal of Emergency Management, 8, 47-54. https://doi.org/10.1080 /oo909880903025929

Spence, P. R., Lachlan, K. A., \& Westerman, D. K. (2009). Presence, sex, and bad news: Exploring the responses of men and women to tragic stories in varying media. Journal of Applied Communication Research, 37, 239-256. https://doi.org/10.1080/00909880903025929

Spence, P. R., Nelson, L. D., \& Lachlan, K. A. (2010). Psychological responses and coping strategies after an urban bridge collapse. Traumatology, 16, 7-15. https://doi.org/10.1177/1534765609347544

Spence, P. R., Westerman, D., Skalski, P., Seeger, M., Sellnow, T., \& Ulmer, R. R. (2006). Gender and age effects on information seeking after 9/11. Communication Research Reports, 23, 217-223. https://doi.org/10.1080 /08824090600796435

Spence, P. R., Westerman, D., Skalski, P., Seeger, M., Ulmer, R., Venette, S., \& Sellnow, T. (2005). Proxemic effects on information seeking following the 9/11 attacks. Communication Research Reports, 22, 39-46. https:// doi:10.1080/0882409052000343507

Tanner, A., Friedman, D. B., Koskan, A., \& Barr, D. (2009). Disaster communication on the Internet: A focus on mobilizing information. Journal of Health Communicaiton: International Perspectives, 14, 741-755. https:// doi.org/10.1080/10810730903295542

Veil, S. R. (2007). Mayhem in the Magic City: Rebuilding legitimacy in a communication train wreck. Public Relations Review, 33, 337-339. https:// doi.org/10.1016/j.pubrev.2007.05.015

Veil, S. R., Reynolds, B., Sellnow, T. L., \& Seeger, M. W. (2008). CERC as a theoretical framework for research and practice. Health Promotion Practice, 9(4), 26-34. https://doi.org/10.1177/1524839908322113

Weick, K. (1995). Sensemaking in organizations. Thousand Oaks, CA: Sage.

Witte, K. (1992). Putting the fear back into fear appeals: The extended parallel process model. Communication Monographs, 59, 329-349. https://doi .org/10.1080/03637759209376276

Zillmann, D. (1999). Exemplification theory: Judging the whole by the sum of its parts. Media Psychology, 1, 69-94. https://doi.org/10.1207/s1532785x mepo101_5

Zillmann, D. (2002). Exemplification theory of media influence. In J. Bryant 
\& D. Zillmann (Eds.), Media effects: Advances in theory and research (2nd ed., pp. 213-245). Mahwah, NJ: Lawrence Erlbaum.

Zillmann, D., Gibson, R., \& Sargent, S. L. (1999). Effects of photographs in news-magazine reports on issue perception. Media Psychology, 1, 207-228. https://doi.org/10.1207/s1532785xmep0103_2

Zoladz, P. R., \& Diamond, D. M. (2008). Hormetic and non-hormetic doseresponse functions in stress effects on memory and synaptic plasticity: Issues and mechanisms. American Journal of Pharmacology and Toxicology, 3 , 108-121. https://doi.org/10.3844/ajptsp.2008.111.124

Zukin, C., \& Snyder, R. (1984). Passive learning: When media environment is the message. Public Opinion Quarterly, 48, 629-638. https://doi.org/10.1086 $/ 268864$ 